\title{
Adherence to a Low Carbohydrate Diet may Modify Resting Metabolic Rate among Overweight and Obese Women
}

\section{Seyedeh Forough Sajjadi}

Tehran University of Medical Sciences

\section{Atieh Mirzababaei}

Tehran University of Medical Sciences

nasim Ghodoosi

Tehran University of Medical Sciences

\section{Sara Pooyan}

Tehran University of Medical Sciences

\section{Hana Arghavani}

Tehran University of Medical Sciences

\section{Niloufar Rasaei}

Tehran University of Medical Sciences

\section{Elaheh Rashidbeygi}

Tehran University of Medical Sciences

\section{Mir-Saeed Yekaninejad}

Tehran University of Medical Sciences

Khadijeh - mirzaei ( $\Delta$ mirzaei_kh@tums.ac.ir)

dr https://orcid.org/0000-0003-3631-7723

\section{Research}

Keywords: Resting metabolic rate, obesity, overweight, low carbohydrate diet, deviation of normal RMR

Posted Date: July 28th, 2020

DOI: https://doi.org/10.21203/rs.3.rs-47451/v1

License: (c) (i) This work is licensed under a Creative Commons Attribution 4.0 International License. Read Full License 


\section{Abstract \\ Objective}

Resting metabolic rate (RMR) accounts for most of the daily energy expenditure. The low-carb diet attenuates decreases in RMR. This study aims to investigate the relationship between a low-carb diet and resting metabolic rate status.

\section{Methods}

We enrolled 304 overweight and obese women in this cross-sectional study. BMI, fat mass, fat-free mass, visceral fat, insulin level were assessed. RMR was measured using indirect calorimetry. A low carbohydrate diet score was measured using a validated semi-quantitative food frequency questionnaire (FFQ).

\section{Results}

Our results showed no relationship between LCDS and DNR even after adjust for confounders (Inc. RMR: OR: 0.97; 95\% Cl: 0.92-1.01, P= 0.20; Dec. RMR: OR: 0.97; 95\% Cl: 0.94-1.00, P=0.14). Some components of LCDS had significant differences with DNR, such as carbohydrate and Dec. RMR in adjusted model (OR: 1.62; 95\% Cl: 0.98-1.37, P = 0.08), MUFA and Dec. RMR in adjusted model (OR: 0.48; 95\% Cl: $0.21-$ $1.10, P=0.08)$ and refined grain and Inc. RMR in crude model (OR: $0.87 ; 95 \% \mathrm{Cl}: 0.77-0.99, \mathrm{P}=0.04)$.

\section{Conclusion}

Our study showed that there is no association between a low-carb diet and RMR status but carbohydrate, MUFA, and refined grain had a significant relationship.

\section{Background}

Obesity, which is a serious, current health problem, affects 400 million adults worldwide [1]. Obesity is also a major public health problem in Iran, where $21.7 \%$ percent of the adult populations are obese [2]. Obesity is characterized as a chronic multifactorial disorder with a genetic basis, which is caused by surplus fat tissue accumulation. It leads to many severe comorbidities, such as insulin resistance, hypertension, development of dyslipidemia, and diabetes mellitus [1, 3-5]; in many countries, nutritional tendencies towards high fat and high energy foods, as well as low physical activity are among the main factors contributing the increase in the incidence of obesity [2]. The traditional treatment for obesity includes a combination of low-calorie diet therapy with enhanced physical activity and nutritional education [1]. Part of the solution might be to prescribe the most suitable diet for each subject, based on 
eating habits, desires, and patterns [6]. Although low-fat diets and energy-restricted diets are commonly advised diets for weight loss, low-carbohydrate diets (low-carb diet) are also a popular choice [7].

Low-carbohydrate diets restrain caloric intake by decreasing the consumption of carbohydrates to 20 to $60 \mathrm{~g} /$ day (typically less than $45 \%$ of the daily caloric intake) while enhancing protein and fat $[6,8]$. Lowcarbohydrate, high-fat and high-protein diets (referred to as low-carb diets) effectively improve weight loss, as well as providing notable improvements in lipid profiles and glycemic control $[9,10]$. The high protein content is satiating, and ketosis has an anorectic outcome, accounting for suppressed appetite. Some studies are showing that low-carb diets result in rapid weight loss because of increased energy expenditure via ketogenesis, or simply by appetite repression because of the high protein content. Protein is more satiating than carbohydrates and fats, both in the long term and short term, and it seems to influence thermogenesis, thereby influencing satiety [1].

Resting metabolic rate (RMR) accounts for $60-75 \%$ of daily energy expenditure in sedentary people [11]. Several studies have recommended that low-carb diets ( $<45 \%$ energy from carbohydrates) attenuate decreases in RMR, with proposed mechanisms including changed substrate availability and endocrinemediated influences on anabolic and catabolic pathways. Furthermore, some studies have recommended that low-carb diets may support the preservation of fat-free mass (FFM) and preferential loss of fat mass, which would also attenuate decreases in RMR [12].

To the best of the researchers' knowledge, this is the first study to investigate the relationship between resting metabolic rate status and low-carbohydrate-diet score (LCDS) in an adult population. Accordingly, this study was carried out to examine LCDS with the deviation of normal RMR (DNR) among a group of adult Iranian women.

\section{Materials And Methods \\ 2.1. Participants}

This cross-sectional research included 304 adult women aged between 18 and 56, who had been referred to health centers in Tehran. Blood samples and anthropometric measurements were taken in the Nutrition and Biochemistry Laboratory of the School of Nutritional and Dietetics at Tehran University of Medical Sciences. Participants were in good general health, with a body mass index (BMI) in the range of 25$49 \mathrm{~kg} / \mathrm{m}^{2}$. This study was conducted according to the guidelines laid down in the Declaration of Helsinki and all procedures involving human subjects were approved by the Ethics Commission of Tehran University of Medical Sciences (IR.TUMS.VCR.REC.1395.1597), and all participants signed written informed consent. The exclusion criteria for the study were as follows: regular use of medicine (including oral contraceptive pill), history of hypertension, cardiovascular disease, diabetes mellitus, and impaired renal and liver function, alcohol use, smoking, pregnancy, lactation period, and menopause. Furthermore, participants were excluded from a chronic disease affecting their diet, as well as those who had been 
following an arbitrary special dietary regimen, and also those with any significant body weight fluctuations over the past 1 year.

\subsection{Energy Expenditure Measurements}

Resting metabolic rate was measured by indirect calorimetry (spirometer METALYZERR 3B-R3, Cortex Biophysik GmbH, Leipzig, Germany). According to the manufacturer's instructions, gas ventilation and exchange is calibrated before each test. Its high-resolution spiroergometric systems use an infrared sensor for $\mathrm{CO}_{2}$ evaluation and an amperometric solid electrolyte sensor for $\mathrm{O}_{2}$ evaluation, which is recorded continuously through breath-by-breath gas analysis. Utilizing an ergonomically designed mask, a small portion of breathed air is conducted through the volume flow sensor. The RMR is evaluated by measuring the amount of $\mathrm{O}_{2}$ consumed and $\mathrm{CO}_{2}$ produced. The RMR was assessed in the morning, after a comfortable night's sleep, and following a 10-12 hour fast. Participants were asked to avoid caffeine or alcohol consumption and severe exercise for a day before RMR measurements. After reclining in a steady-state and a supine position in a quiet room, the RMR was measured for 30 min. The respiratory exchange ratio and oxygen uptake $\left(\mathrm{VO}_{2}\right)$ were analyzed within the middle 20 min of the resting period. Predictive RMR was determined using the Harris-Benedict equation, which considers the weight, height, and age of participants.

\subsection{Body Composition Measurement}

Body composition, including weight, BMI, fat mass, and FFM were acquired using a multi-frequency bioelectrical impedance analyzer InBody 770 scanner (Inbody Co., Seoul, Korea). This electrical impedance analyzer calculates the resistance of body tissues to the flow of an electrical signal sent through both hands and feet. The amount and proportion of bodily fat-free mass and fat mass can be measured as the current flows more efficiently through certain parts of the body. According to the manufacturer's instructions, after shoes, coats, and sweaters had been removed, subjects were required to stand on the balance scale in bare feet and grasp the handles of the machine. The measurements take approximately 20 seconds, and the output is printed.

\subsection{Biochemical Parameters and Hormonal Assay}

Venous blood samples were collected in the morning (8-10 A.M.) after 10-12 hours fasting by a qualified phlebotomist. Within 30 to 45 min after each sample was collected, the blood was centrifuged for $15 \mathrm{~min}$. Following separation, the serum was removed and frozen at $-80^{\circ} \mathrm{C}$ for later analysis. Fasting blood glucose (FBG) levels were evaluated by a colorimetric method based on the GOD-PAP method, triglyceride (TG) was assessed by GPO-PAP, and low-density lipoprotein cholesterol (LDL-c) was evaluated by the direct method. An immunoinhibition assay was used for the measurement of highdensity lipoprotein cholesterol (HDL-c) and total cholesterol levels. Pars Azmoon kit was used for all assessments (Pars Azmoon Inc. Tehran, Iran) other than insulin. Serum insulin concentrations were analyzed by enzyme-linked immunosorbent assay (ELISA) method (Human insulin ELISA kit, Monobind Inc., Lake Forest, USA). All measurements were taken at the Nutrition and Biochemistry Laboratory of the School of Nutritional Sciences and Dietetics. 


\subsection{Deviation of Normal RMR and Calculation Method}

After examining the values of the body composition analysis, RMR components, and biochemical characters and comparing them with RMR status, the participants were categorized into 3 groups: increased RMR (Inc. RMR), normal RMR, and decreased RMR (Dec. RMR), based on the score of the deviation from normal RMR. Deviation of normal RMR was measured by indirect calorimetry (METALYZERR 3B-R3). The cutoff points for the groups were as follows: Inc. RMR ( $>5 \%$ SD of normal RMR), normal RMR $(-5 \%$ SD $<$ normal RMR $<5 \%$ SD), and Dec. RMR (normal RMR $<-5 \% S D$ ).

\subsection{HOMA and QUICKI Calculations}

Insulin resistance was estimated by homeostasis model assessment (HOMA). The HOMA was calculated according to the following equation: HOMA $=$ [Fasting Plasma Glucose $(\mathrm{mmol} / \mathrm{L}) \times$ Fasting Plasma Insulin (mIU/L)]/22.5 [13]. Insulin sensitivity quantitative insulin sensitivity check index (ISQUICKI) was assessed by: ISQUICKI = 1/[log (fasting insulin) + log (fasting glucose)] [14] .

\subsection{Calculation of Low-Carbohydrate-Diet Score}

A validated and reliable 168-item food frequency questionnaire (FFQ) was used to assess the dietary intake of participants. This semi-quantitative questionnaire consists of standard portion sizes for each food item and has been designed according to the Willett method. Participants were asked to determine the frequency of consumption of each food item during the previous year, based on serving sizes. The validity and reliability of the FFQ were determined previously [15]. Food intakes reported in household measures were then converted to grams of food per day using the nutritionist IV software. LCDS was measured for each subject. The participants included in the current study were divided into 11 strata based on their scores in the following seven categories: carbohydrates refined grains, vegetable protein intake, monounsaturated fatty acids (MUFA), n3/n6 polyunsaturated fatty acids (PUFA) (expressed as a percentage of energy intake), as well as fiber (gr/1000 Kcal), and glycemic load (GL). Dietary GL was estimated as (total glycemic index * total available carbohydrate)/100 [16] and expressed as $\mathrm{gr} / \mathrm{d}$. Women in the lowest stratum of refined grains, carbohydrates and GL were given a score of 10 , and those in the highest stratum were given a score of 0 . For n3/n6 PUFA, MUFA, fiber, and vegetable protein intake, the order of the strata were reversed. The points for the seven items were added together to create the overall score, named the "low carbohydrate diet score", which ranged from 0 (the highest carbohydrate intake and the lowest fat and protein intake) to 70 (the lowest carbohydrate intake and the highest protein and fat intake). Therefore, higher LCDS scores demonstrated closer adherence to low-carb diets [17].

\subsection{Assessment of Other Variables}

Physical activity levels were measured by a validated questionnaire (International Physical Activity Questionnaire-Short Form) that also included leisure, occupational commuting, and housework activities [18]. For height measurements, subjects were in a standing position without shoes, in contact with the wall with their head, shoulders, heels, and hips, and their height was recorded to the nearest $0.1 \mathrm{~cm}$.

\subsection{Statistical Analysis}


All statistical analysis was performed using the IBM SPSS software version 22.0 (SPSS, Chicago, IL, USA). Normal distribution of data was checked by the Kolmogorov-Smirnov test. An independent sample t-test was used for assessed differences between groups with low and high adherence to low-carb diets. The differences between RMR status groups were assessed by one-way ANOVA and re-analyses by the general linear model (GLM) were performed to adjust for confounders' effects. Collinear variables did not enter into the model. Post-Hoc Multiple Comparison analysis resulted from the LCD procedure was used to demonstrate the significant differences between groups. Multinomial logistic regression was used to assess the association of DNR and LCDS and its components. Four models were constructed: Model 1 was adjusted for age, model 2 was adjusted for FFM, model 3 was adjusted for physical activity, and model 4 additionally adjusted for energy intake. Results were presented as odds ratios (ORs) and 95\% confidence intervals (Cls) compared with the DNR groups.

\section{Results}

\subsection{Study Population Characteristics}

Three hundred and four healthy obese women enrolled in this cross-sectional study. The mean age, height, weight, and BMI of the study participants were 36.49 years $(S D=8.38), 161.38 \mathrm{~cm}(S D=5.90)$, $80.89 \mathrm{~kg}(\mathrm{SD}=12.45)$, and $31.04 \mathrm{~kg} / \mathrm{m} 2$ (SD=4.31), respectively (Table 1). The mean body composition, RMR components, biochemical and anthropometric characteristics of subjects are shown in Table 1.

\subsection{Study Participant Characteristics between High and Low Adherence of Low-Carb Diet}

All participants were categorized based on the LCDS and divided into two groups (Table 2). The differences between the low and high adherence of the low-carb diet groups were analyzed through independent sample t-test for RMR components, body composition analysis, and biochemical characteristics. As shown in Table 2, participants with high adherence to a low-carb diet had significantly higher LDL-C $(P=0.03)$. However, subjects with high adherence to a low-carb diet had higher total cholesterol $(P=0.22)$ and HDL-c $(P=0.10)$, compared to the low adherence low-carb diet group, but these findings were not statistically significant. There were no significant differences in terms of height, weight, RMR, RMR/kg body weight, normal deviation, Respiratory Quotient, FFM, FBS, and TG between the two groups $(P>0.05)$ (Table 2).

\subsection{Association of Studied Variations and RMR Status}

By considering the association of body composition analysis, RMR components and biochemical characters with RMR status, the participants were categorized into 3 groups; Inc. RMR $(n=37)(>5 \%$ SD of normal RMR), normal RMR ( $n=87)(-5 \%$ SD $<$ normal RMR $<5 \%$ SD), and Dec. RMR $(n=172)$ (normal RMR $<$ $-5 \%$ SD). The differences between the normal, Dec. and Inc. RMR groups were analyzed through one-way ANOVA tests (Table 3$)$. Subjects in Inc. RMR group had significantly higher height $(P<0.006)$, RMR measurement $(P<0.0001), R M R / k g$ body weight $(P<0.0001)$, skeletal muscle mass $(P<0.0001)$, and soft lean mass $(P<0.0001)$, compared to the Dec. RMR group. All significant results remained robust 
after adjusting for age, energy intake, physical activity, and FFM. Furthermore, bodily fat mass $(P=0.01)$ and ISQUICKI $(P=0.02)$ became significant (Table 3).

\subsection{The Association of LCDS and RMR across Deviation of Normal RMR}

Multivariate-adjusted models with 95\% confidence intervals for the association between LCDS and RMR across DNR are presented in Table 4. In the crude model, no significant association was found between LCDS with Inc. and Dec. RMR (For Inc. RMR: OR: 0.97; 95\% Cl: 0.93-1.01, P=0.20; for Dec. RMR: OR: 0.98; $95 \% \mathrm{Cl}: 0.96-1.01, \mathrm{P}=0.31)$. Furthermore, after adjustment for confounders including age, FFM, physical activity, and energy intake in the final model, the associations remained unchanged. Therefore, no significant association was found between LCDS with Inc. and Dec. RMR (For Inc. RMR: OR: 0.97; 95\% Cl: 0.92-1.01, P=0.20; For Dec. RMR: OR: 0.97; 95\% Cl: 0.94-1.00, $P=0.14$ ).

The Association of LCDS Components and RMR across Deviation of Normal RMR

The participants' dietary components of LCDS, based on DNR groups, are shown in Table 5. Differences in some LCDS components between DNRs were non-significant: GL, vegetable protein intake, n3/n6 PUFA, and fiber (gr/1000Kcal) - even after adjustment for the potential confounders. However, the crude differences in carbohydrates (\% energy) between the DNRs were not significant (Dec. RMR: OR: 1.11; 95\% Cl: 0.95-1.30, $P=0.15$, Inc. RMR: OR: 1.20; 95\% Cl: 0.95-1.51, $P=0.11)$, but after controlling for confounders like age, FFM, physical activity, and energy intake, the association became marginally significant for Dec. RMR (OR: 0.15; 95\% Cl: 0.98-1.37, $\mathrm{P}=0.08$ ). Also, MUFA in the crude model was not significant (Dec. RMR: OR: $0.58 ; 95 \%$ Cl: $0.27-1.24, \mathrm{P}=0.0 .16$, Inc. RMR: OR: $0.65 ; 95 \% \mathrm{Cl}: 0.21-0.03, \mathrm{P}=0.46)$, but after controlling for confounders, showed a marginally significant association with Dec. RMR (OR: 0.48; 95\% Cl: 0.21-1.10, $P=0.08$ ). For refined grains, participants with a higher intake were at a $13 \%$ lower risk for Inc. RMR (OR: $0.87 ; 95 \% \mathrm{Cl}: 0.77-0.99, \mathrm{P}=0.04)$. However, after adjusting for confounders, the significance disappeared (OR: 0.93; 95\% Cl: 0.81-1.08, $\mathrm{P}=0.39$ ).

\section{Discussion}

In an effort to address the issue of obesity and increased adipose tissue, the present study aimed to examine the mediatory role of a low-carb diet and its components on body weight. Several fields of study have suggested that overweight and obesity have both rapidly increased worldwide in recent decades [19]. One of the ways to control body weight is to increase RMR. However, a low-carb diet might be able to reduce the development of obesity. Previous studies had indicated links between low-carb diets and obesity [20]. Therefore, this paper sought to test the effect of LCDS on the possible link between obesity and deviation of normal RMR in overweight and obese women.

The findings of the current study indicate that high adherence to a low-carb diet is associated with higher LDL-c. This result may be attributed to the replacement of carbohydrates with fats in a low-carb diet [21]. This finding was consistent with previous observations that fat intake results in an increase in LDL-c [22]. Also, this result showed the association between a low-carb diet and increases in total cholesterol and 
HDL-c. Based on previous studies, lower dietary intake of carbohydrates has been associated with higher concentrations of HDL-c [21, 23].

The other finding of this research is that increased RMR is strongly associated with higher height, $\mathrm{RMR} / \mathrm{kg}$ body weight, skeletal muscle mass, soft lean mass, and ISQUICKI. These findings were in line with a previous finding which showed that, in women with up to $40 \%$ body fat, fat mass was associated with increased metabolic rate [24]. Low RMR is associated with increased fat mass and weight [25]. The excess fat mass has a significant influence on metabolic function [26]. However, in obese and overweight individuals, the fat mass has a greater metabolic impact [27], both directly, by altering substrate oxidation and metabolic rate, and indirectly, by chronic changes in hormonal concentrations [26], with skeletal muscle being the most easily manipulated contributor to RMR. Lean mass, which includes both organ tissue and skeletal muscle, accounts for $60-70 \%$ and $20-30 \%$ of RMR, respectively [28]. Muscle mass specifically is the main location for substrate oxidation and is correlated with enhanced health status, including improved insulin and glucose adjustment, but the correlation between body composition (specifically metabolic function) and lean mass is still unclear [29].

This study found no significant association between LCDS and RMR status. This result is in line with previous studies which showed that low-carb diets failed to increase energy expenditure compared to lowfat diets [20]. The current study also investigated the relationship between the components of a low-carb diet and DNR. After adjustment for age, physical activity, FFM, and energy intake, a significant relationship was observed between carbohydrates, MUFA, and refined grain on the one hand, and DNR on the other. Moreover, previous studies have suggested that dietary carbohydrates are among the factors thought to influence metabolic adaptation [12]. However, the current findings are in agreement with those findings that proposed that reducing dietary carbohydrates may decrease reductions in RMR through mechanisms associated with substrate availability, and autonomic and hormonal activity [30].

Contrary to the results of this study, Gillingham et al. reported that there was no significant correlation between the consumption of MUFA and modulate resting or postprandial energy expenditure [31]. However, findings from other studies have reported that dietary increases in MUFA [32,33], and the ratio of MUFA to saturated fatty acid or polyunsaturated fatty acid, increased the thermic effect of food, and/or fat oxidation $[34,35]$. More specifically, MUFA is more powerful than saturated fatty acids in upregulating PPARa expression, inducing the transcription of genes associated with thermogenesis and fat oxidation, while suppressing the genes regulating fatty acid synthesis [31]. However, in the present study, there were no associations seen between vegetable protein intake, fiber, $\mathrm{n} 3 / \mathrm{n} 6$ ratio, and DNR.

Less is known about the potential influence of basal blood hormones like insulin on RMR [36]. Astrup and colleagues [37] have reported a moderate correlation between insulin and RMR in females [36]. Moreover, previous studies revealed significant differences in RMR in individuals with insulin resistance [38, 39]. More indirect support for the association between RMR and insulin comes from studies describing higher RMR in individuals with type 2 diabetes, contrasted with non-diabetics, which has been suggested, is due to insulin resistance [36]. Refined grains had diminished insulin sensitivity, and one of the first responses 
to alternations in insulin sensitivity is the change in hepatic insulin clearance rates [40]. The physiological mechanisms responsible for elevated RMR in individuals with insulin resistance are poorly understood. Several mechanisms have been suggested to explain the increased RMR, including futile substrate cycling, plasma glucagon, increases in protein turnover, and sympathetic nervous system activity [41]. The other proposed mechanism that revealed the correlation between RMR and insulin resistance was an increase in gluconeogenesis. It has been put forward that enhanced free fatty acid concentrations in individuals with insulin resistance contribute to increased hepatic glucose output and excessive rates of gluconeogenesis, depending upon the fatty acids oxidation and consequently the increased energy expenditure rate in these samples [41, 42]. In support of this pathway, following improvements in glycemic control, a decrease in resting energy expenditure was reported.

\section{Conclusion}

In conclusion, this study's nuanced findings do highlight that a low-carb diet has no significant correlation with DNR, but some of the components of this diet, like refined grains, MUFA, and carbohydrates, revealed significant associations. This could lead to practical strategies to assist in the control or prevention of overweigh and obesity and related disorders in community.

To the researchers' knowledge, this study was the first to assess the possible relationship between lowcarb diets and DNR in obese women. Studies of the possible link between this low-carb diet and DNR in obese people require more clinical trials, as well as further cohort research designs. The major limitation of our study was the relatively small number of participants and the same-sex sample. Also, due to the study type, causality is not able to be determined.

\section{Abbreviations}

RMR: resting metabolic rate, FFM: fat free mass, LCDS: low-carbohydrate-diet score, DNR: deviation of normal RMR, GL: glycemic load, FBG: Fasting blood glucose, TG: triglyceride ,LDL-c: low-density lipoprotein cholesterol ,HDL-c: high-density lipoprotein cholesterol, MUFA: monounsaturated fatty acids, PUFA: polyunsaturated fatty acids, ISQUICKI: Insulin sensitivity quantitative insulin sensitivity check index

\section{Declarations}

\section{Authors' contributions}

The project was designed and implemented by SFS and KhM. Data were analyzed and interpreted SFS, $\mathrm{AM}, \mathrm{NGH}, \mathrm{AP}, \mathrm{HA}, \mathrm{NR}$, ER and SY prepared the manuscript. KhM, supervised overall project. All authors read and approved the fnal manuscript.

\section{Acknowledgements}


The authors thank the study participants for their cooperation and assistance in physical examinations. They also thank those involved in nutritional evaluation and database management, as well as Tehran University of Medical Sciences.

\section{Competing interests}

The authors declare that they have no competing interests.

\section{Availability of data and materials}

The data that support the fndings of this study are available from Khadijeh Mirzaei but restrictions apply to the availability of these data, which were used under license for the current study, and so are not publicly available. Data are however available from the authors upon reasonable request and with permission of Khadijeh Mirzae

\section{Consent for publication}

Each participant was completely informed about the study protocol and provided a written and informed consent form before taking part in the study.

\section{Ethics approval and consent to participate}

The study protocol has approved by the ethics committee of Endocrinology and Metabolism Research Center of Tehran University of Medical Sciences (TUMS) with the following identifcation: ID: 96-01-16134479, 95-04-161-33893.

\section{Funding}

This study was supported by Tehran University of Medical Sciences, and by Grants from Tehran University of Medical Sciences ID: 96-01-161-34479, 95-04-161-33893.

\section{References}

1. Triffoni-Melo Ade T, Dick-de-Paula I, Portari GV, Jordao AA, Garcia Chiarello P, Diez-Garcia RW. Shortterm carbohydrate-restricted diet for weight loss in severely obese women. Obes Surg. 2011;21(8):1194-202.

2. Rahmani A, Sayehmiri K, Asadollahi K, Sarokhani D, Islami F, Sarokhani M. Investigation of the Prevalence of Obesity in Iran: a Systematic Review and Meta-Analysis Study. Acta medica Iranica. 2015;53(10):596-607.

3. Bastien M, Poirier P, Lemieux I, Despres JP. Overview of epidemiology and contribution of obesity to cardiovascular disease. Prog Cardiovasc Dis. 2014;56(4):369-81.

4. Sajjadi SF, Mirzaei K, Khorrami-Nezhad L, Maghbooli Z, Keshavarz SA. Vitamin D Status and Resting Metabolic Rate May Modify through Expression of Vitamin D Receptor and Peroxisome Proliferator- 
Activated Receptor Gamma Coactivator-1 Alpha Gene in Overweight and Obese Adults. Ann Nutr Metab. 2017;72(1):43-9.

5. Rahimlou M, Mirzaei K, Keshavarz SA, Hossein-Nezhad A. Association of circulating adipokines with metabolic dyslipidemia in obese versus non-obese individuals. Diabetes Metab Syndr. 2016;10(1 Suppl 1):9.

6. Last AR, Wilson SA. Low-carbohydrate diets. Am Fam Physician. 2006;73(11):1942-8.

7. Essah PA, Levy JR, Sistrun SN, Kelly SM, Nestler JE. Effect of weight loss by a low-fat diet and a lowcarbohydrate diet on peptide YY levels. IJO. 2010;34(8):1239-42.

8. Hu T, Mills KT, Yao L, Demanelis K, Eloustaz M, Yancy Jr, et al. Effects of low-carbohydrate diets versus low-fat diets on metabolic risk factors: a meta-analysis of randomized controlled clinical trials. Am J Epidemiol 2012;0ct 1;176(suppl_7):S44-54.

9. Tonstad S, Malik N, Haddad E. A high-fibre bean-rich diet versus a low-carbohydrate diet for obesity. J Hum Nutr Diet. 2014;27(Suppl 2):109-16.

10. Grieb P, Klapcinska B, Smol E, Pilis T, Pilis W, Sadowska-Krepa E, et al. Long-term consumption of a carbohydrate-restricted diet does not induce deleterious metabolic effects. Nutr Res. 2008;28(12):825-33.

11. Thompson JL, Manore MM, Thomas JR. Effects of diet and diet-plus-exercise programs on resting metabolic rate: a meta-analysis. Int J Sport Nutr. 1996;6(1):41-61.

12. Karl JP, Roberts SB, Schaefer EJ, Gleason JA, Fuss P, Rasmussen H, et al. Effects of carbohydrate quantity and glycemic index on resting metabolic rate and body composition during weight loss. Obesity (Silver Spring Md). 2015;23(11):2190-8.

13. Matthews D, Hosker J, Rudenski A, Naylor B, Treacher D, Turner R. Homeostasis model assessment: insulin resistance and $\beta$-cell function from fasting plasma glucose and insulin concentrations in man. Diabetologia. 1985;28(7):412-9.

14. Katz A, Nambi SS, Mather K, Baron AD, Follmann DA, Sullivan G, et al. Quantitative insulin sensitivity check index: a simple, accurate method for assessing insulin sensitivity in humans. J Clin Endocrinol Metab. 2000;85(7):2402-10.

15. Azadbakht L, Haghighatdoost F, Feizi A, esmaeilzade A. Breakfast eating pattern and its association with dietary quality indices and anthropometric measurements in young women in Isfahan. Nutrition. 2013;29(2):420-5.

16. Wolever TM, Yang M, Zeng XY, Atkinson F, Brand-Miller JC. Food glycemic index, as given in glycemic index tables, is a significant determinant of glycemic responses elicited by composite breakfast meals. Am J Clin Nutr. 2006;83(6):1306-12.

17. Azizi F. Low carbohydrate diet score does not predict metabolic syndrome in children and adolescents: Tehran Lipid and Glucose Study. Arch Iran Med. 2014;17(6):417.

18. Craig CL, Marshall AL, Sjöström M, Bauman AE, Booth ML, Ainsworth BE, et al. International physical activity questionnaire: 12-country reliability and validity. Med Sci Sports Exerc. 2003;35(8):1381-95. 
19. Kyle RG, Wills J, Mahoney C, Hoyle L, Kelly M, Atherton IM. Obesity prevalence among healthcare professionals in England: a cross-sectional study using the Health Survey for England. BMJ Open. 2017;7(12):2017-018498.

20. Erlanson-Albertsson C, Mei J. The effect of low carbohydrate on energy metabolism. Int J Obes. 2005;29(2):26-30.

21. Tay J, Luscombe-Marsh ND, Thompson CH, Noakes M, Buckley JD, Wittert GA, et al. Comparison of low- and high-carbohydrate diets for type 2 diabetes management: a randomized trial. Am J Clin Nutr. 2015;102(4):780-90.

22. Dreon DM, Fernstrom HA, Campos H, Blanche P, Williams PT, Krauss RM. Change in dietary saturated fat intake is correlated with change in mass of large low-density-lipoprotein particles in men. Am J Clin Nutr. 1998;67(5):828-36.

23. Shirani F, Esmaillzadeh A, Keshteli AH, Adibi P, Azadbakht L. Low-carbohydrate-diet score and metabolic syndrome: An epidemiologic study among Iranian women. Nutrition. 2015;31(9):1124-30.

24. Bosy-Westphal A, Muller MJ, Boschmann M, Klaus S, Kreymann G, Luhrmann PM, et al. Grade of adiposity affects the impact of fat mass on resting energy expenditure in women. $\mathrm{Br} \mathrm{J}$ Nutr. 2009;101(4):474-7.

25. Piaggi P, Thearle MS, Bogardus C, Krakoff J. Lower energy expenditure predicts long-term increases in weight and fat mass. J Clin Endocrinol Metab. 2013;98(4):2012-3529.

26. Shook RP, Hand GA, Paluch AE, Wang X, Moran R, Hebert JR, et al. High respiratory quotient is associated with increases in body weight and fat mass in young adults. Eur $\mathrm{J}$ Clin Nutr. 2016;70(10):1197-202.

27. Carneiro IP, Elliott SA, Siervo M, Padwal R, Bertoli S, Battezzati A, et al. Is Obesity Associated with Altered Energy Expenditure? Adv Nutr. 2016;7(3):476-87.

28. Dulloo AG, Jacquet J, Solinas G, Montani JP, Schutz Y. Body composition phenotypes in pathways to obesity and the metabolic syndrome. Int J Obes. 2010;34(2):234.

29. Hirsch KR, Smith-Ryan AE, Blue MNM, Mock MG, Trexler ET. Influence of segmental body composition and adiposity hormones on resting metabolic rate and substrate utilization in overweight and obese adults. J Endocrinol Invest. 2017;40(6):635-43.

30. Ebbeling CB, Swain JF, Feldman HA, Wong WW, Hachey DL, Garcia-Lago E, et al. Effects of dietary composition on energy expenditure during weight-loss maintenance. Jama. 2012;307(24):2627-34.

31. Gillingham LG, Robinson KS, Jones PJ. Effect of high-oleic canola and flaxseed oils on energy expenditure and body composition in hypercholesterolemic subjects. Metabolism. 2012;61(11):1598-605.

32. Jones PJ, Jew S, AbuMweis S. The effect of dietary oleic, linoleic, and linolenic acids on fat oxidation and energy expenditure in healthy men. Metabolism. 2008;57(9):1198-203.

33. Kien CL, Bunn JY, Tompkins CL, Dumas JA, Crain KI, Ebenstein DB, et al. Substituting dietary monounsaturated fat for saturated fat is associated with increased daily physical activity and resting energy expenditure and with changes in mood. Am J Clin Nutr. 2013;97(4):689-97. 
34. Casas-Agustench P, Lopez-Uriarte P, Bullo M, Ros E, Gomez-Flores A, Salas-Salvado J. Acute effects of three high-fat meals with different fat saturations on energy expenditure, substrate oxidation and satiety. Clin Nutr. 2009;28(1):39-45.

35. Moradi S, Mirzaei K, Abdurahman AA, Keshavarz SA. Adipokines may mediate the relationship between resting metabolic rates and bone mineral densities in obese women. Osteoporos Int. 2017;28(5):1619-29.

36. Wright TG, Dawson B, Jalleh G, Guelfi KJ. Influence of Hormonal Profile on Resting Metabolic Rate in Normal, Overweight and Obese Individuals. Ann Nutr Metab. 2015;66(2-3):162-7.

37. Astrup A, Buemann B, Christensen NJ, Madsen J, Gluud C, Bennett P, et al. The contribution of body composition, substrates, and hormones to the variability in energy expenditure and substrate utilization in premenopausal women. J Clin Endocrinol Metab. 1992;74(2):279-86.

38. Weyer C, Bogardus C, Pratley RE. Metabolic factors contributing to increased resting metabolic rate and decreased insulin-induced thermogenesis during the development of type 2 diabetes. Diabetes. 1999;48(8):1607-14.

39. Moradi S, Mirzaei K, Abdurahman AA, Keshavarz SA, Hossein-Nezhad A. Mediatory effect of circulating vaspin on resting metabolic rate in obese individuals. Eur J Nutr. 2016;55(3):1297-305.

40. Kim Y, Keogh JB, Clifton PM. Differential Effects of Red Meat/Refined Grain Diet and Dairy/Chicken/Nuts/Whole Grain Diet on Glucose, Insulin and Triglyceride in a Randomized Crossover Study. Nutrients 2016;8(11).

41. Fontvieille AM, Lillioja S, Ferraro RT, Schulz LO, Rising R, Ravussin E. Twenty-four-hour energy expenditure in Pima Indians with type 2 (non-insulin-dependent) diabetes mellitus. Diabetologia. 1992;35(8):753-9.

42. Hussain Z, Khan JA. Food intake regulation by leptin: Mechanisms mediating gluconeogenesis and energy expenditure. Asian Pac J Trop Med. 2017;10(10):940-4.

\section{Tables}


Table.1 Study population characteristics

\begin{tabular}{|c|c|c|c|}
\hline Parameters & Minimum & Maximum & Mean \pm SD \\
\hline Age (years) & 17 & 56 & $36.49 \pm 8.38$ \\
\hline Height (cm) & 142 & 179 & $161.38 \pm 5.90$ \\
\hline Weight (kg) & 59.50 & 136.60 & $80.89 \pm 12.45$ \\
\hline BMI $\left(\mathrm{kg} / \mathrm{m}^{2}\right)$ & 24.20 & 49.60 & $31.04 \pm 4.31$ \\
\hline \multicolumn{4}{|l|}{ RMR parameters } \\
\hline RMR measure (kcal/day) & 952.00 & 2480.00 & $1575.00 \pm 259.71$ \\
\hline RMR normal (kcal/day) & 1425.00 & 2548.00 & $1720.40 \pm 152.36$ \\
\hline Deviation normal (\%) & -44.00 & 40.00 & $-8.47 \pm 12.59$ \\
\hline RMR/kg body weight ( $\mathrm{kcal} / \mathrm{day} / \mathrm{kg}$ ) & 9.30 & 32.50 & $19.59 \pm 3.09$ \\
\hline \multicolumn{4}{|l|}{ Body composition analysis } \\
\hline Body fat mass $(\mathrm{kg})$ & 19.40 & 74.20 & $34.04 \pm 8.69$ \\
\hline Fat free mass $(\mathrm{kg})$ & 35.30 & 67.70 & $46.80 \pm 5.64$ \\
\hline Skeletal muscle mass (kg) & 18.90 & 37.90 & $25.69 \pm 3.33$ \\
\hline Soft lean mass $(\mathrm{kg})$ & 26.10 & 63.80 & $44.02 \pm 5.37$ \\
\hline \multicolumn{4}{|l|}{ Blood parameters } \\
\hline FBS (mg/dl) & 67.00 & 137.00 & $87.49 \pm 9.64$ \\
\hline Insulin (mIU/ml) & 6.67 & 65.89 & $15.68 \pm 6.06$ \\
\hline T-Chol (mg/dl ) & 104.00 & 344.00 & $185.30 \pm 35.77$ \\
\hline TG (mg/dl ) & 37.00 & 512.00 & $122.11 \pm 69.29$ \\
\hline $\mathrm{HDL}-\mathrm{C}(\mathrm{mg} / \mathrm{dl})$ & 18.00 & 87.00 & $46.58 \pm 10.86$ \\
\hline LDL-C (mg/dl) & 34.00 & 156.00 & $95.30 \pm 24.12$ \\
\hline HOMA & 1.29 & 16.59 & $3.43 \pm 1.53$ \\
\hline ISQUICKI & 0.39 & 0.68 & $0.54 \pm 0.04$ \\
\hline
\end{tabular}

FFM, fat-free mass; FBS, fasting blood sugar; TG, triglyceride; T-chol, total cholesterol; HOMA, homeostasis model assessment; ISQUICKI,: insulin sensitivity quantitative insulin sensitivity check index.

$\mathrm{N}=304$

Data are indicated as Mean \pm SD otherwise indicated 
Page 15/22 
Table 2. Study Participant Characteristics between High and Low Adherence to Low Carb. Diet

\section{Low-Carb Diet **}

\section{Parameters}

Age (years)

Height $(\mathrm{cm})$

Weight $(\mathrm{kg})$

BMI

\section{RMR Parameters}

RMR measure (kcal/day)

RMR normal (kcal/day)

Deviation normal (\%)

$\mathrm{RMR} / \mathrm{kg}$ body weight

( $\mathrm{kcal} / \mathrm{day} / \mathrm{kg}$ )

\section{Body Composition Analysis}

Body fat mass $(\mathrm{kg})$

$34.07 \pm 9.01$

$46.97 \pm 5.68$

Fat free mass $(\mathrm{kg})$

Skeletal muscle mass $(\mathrm{kg})$

Soft lean mass $(\mathrm{kg})$

Blood Parameters

FBS (mg/dl)

$87.01 \pm 9.76$

$16.08 \pm 6.97$

$181.96 \pm 35.00$

$199.87 \pm 67.75$

$45.76 \pm 10.40$

$91.82 \pm 21.13$

$3.51 \pm 1.80$

$0.541 \pm 0.049$

ISQUICKI

HOMA

FFM, fat-free mass; FBS, fasting blood sugar; TG, triglyceride, T-chol, total cholesterol; HOMA, homeostasis model assessment; ISQUICKI, insulin sensitivity quantitative insulin sensitivity check index.

$\begin{aligned} & \text { High-Adherence } \\ & n=159\end{aligned} \quad P^{4} \quad P \$, t, \pm$

$\begin{array}{lll}36.47 \pm 8.56 & 0.96 & 0.62\end{array}$

$\begin{array}{lll}161.46 \pm 5.89 & 0.56 & 0.75\end{array}$

$\begin{array}{lll}80.41 \pm 11.73 & 0.74 & 0.49\end{array}$

$30.86 \pm 4.21 \quad 0.48 \quad 0.50$

$1570.93 \pm 248.76 \quad 0.74 \quad 0.92$

$\begin{array}{lll}1570.93 \pm 248.76 & 0.73 \quad 0.76\end{array}$

$\begin{array}{lll}-8.54 \pm 11.96 & 0.72 & 0.84\end{array}$

$\begin{array}{lll}19.67 \pm 3.04 & 0.92 & 0.49\end{array}$

$\begin{array}{lll}33.84 \pm 8.29 & 0.82 & 0.81\end{array}$

$\begin{array}{lll}46.56 \pm 5.49 & 0.53 & 0.72\end{array}$

$\begin{array}{lll}25.57 \pm 3.28 & 0.86 & 0.78\end{array}$

$\begin{array}{lll}43.69 \pm 5.27 & 0.34 & 0.46\end{array}$

$\begin{array}{lll}87.92 \pm 9.52 & 0.46 & 0.34\end{array}$

$\begin{array}{lll}15.31 \pm 5.35 & 0.31 & 0.22\end{array}$

$\begin{array}{lll}188.23 \pm 37.19 & 0.15 & 0.22\end{array}$

$\begin{array}{lll}124.77 \pm 72.90 & 0.58 & 0.66\end{array}$

$\begin{array}{lll}47.73 \pm 11.19 & 0.15 & 0.10\end{array}$

$\begin{array}{lll}97.89 \pm 26.38 & 0.04 & 0.03\end{array}$

$\begin{array}{lll}3.34 \pm 1.29 & 0.39 & 0.25\end{array}$

$\begin{array}{lll}0.545 \pm 0.048 & 0.55 & 0.41\end{array}$ 
$\mathrm{N}=304$

**This diet is defined based on LCDS. The adherence to a low-carb diet is based on the median of population (cut point=36)

${ }^{*}$ Mean \pm SD. ${ }^{\natural}$ P-values are from ANOVA. § P-values are from general linear model (GLM). ${ }^{\dagger}$ After adjustment for age, FFM, energy intake, and physical activity (METs/d). ${ }^{\ddagger}$ Collinear variables did not enter into the model 
Table 3. Association of Studied Variation and RMR Status

\section{RMR Status}

\begin{tabular}{|c|c|c|c|c|c|}
\hline Parameters & $\begin{array}{l}\text { Dec. RMR } \\
n=172\end{array}$ & $\begin{array}{l}\text { Normal RMR } \\
\mathrm{n}=87\end{array}$ & $\begin{array}{l}\text { Inc. RMR } \\
n=37\end{array}$ & $P^{4}$ & $P \S, t, \neq$ \\
\hline Age (years) & $36.30 \pm 7.92^{*}$ & $30.36 \pm 9.01$ & $37.05 \pm 9.13$ & 0.88 & 0.94 \\
\hline Height (cm) & $160.50 \pm 5.54^{\mathrm{ab}}$ & $162.44 \pm 6.24^{a}$ & $163.25 \pm 6.17^{b}$ & 0.006 & 0.002 \\
\hline Weight (kg) & $80.35 \pm 12.10$ & $80.83 \pm 12.09$ & $83.80 \pm 14.26$ & 0.30 & 0.39 \\
\hline BMI & $31.10 \pm 4.32$ & $30.70 \pm 3.84$ & $31.42 \pm 5.14$ & 0.64 & 0.79 \\
\hline
\end{tabular}

\section{RMR Parameters}

\begin{tabular}{llllll}
$\begin{array}{l}\text { RMR measure } \\
\text { (kcal/day) }\end{array}$ & $1425.00 \pm 179.98^{\mathrm{ab}}$ & $1713.90 \pm 167.01^{\mathrm{ac}}$ & $1945.10 \pm 163.24^{\mathrm{bc}}$ & $\mathbf{0 . 0 0 0 1}$ & $\mathbf{0 . 0 0 0 1}$ \\
\hline $\begin{array}{l}\text { RMR normal } \\
\text { (kcal/day) }\end{array}$ & $1714.40 \pm 151.64$ & $1726.20 \pm 149.64$ & $1734.60 \pm 164.42$ & 0.70 & 0.66 \\
\hline $\begin{array}{l}\text { RMR/kg body } \\
\text { weight } \\
\text { (kcal/day/kg) }\end{array}$ & $17.83 \pm 2.17^{\mathrm{ab}}$ & $21.19 \pm 1.65^{\mathrm{ac}}$ & $24.03 \pm 2.90^{\mathrm{bc}}$ & $\mathbf{0 . 0 0 0 1}$ & $\mathbf{0 . 0 0 0 1}$ \\
\hline
\end{tabular}

\section{Body Composition Analysis}

\begin{tabular}{lccccc}
$\begin{array}{l}\text { Body fat mass } \\
(\mathrm{kg})\end{array}$ & $34.33 \pm 8.54$ & $33.66 \pm 8.10$ & $33.85 \pm 10.49$ & 0.81 & 0.01 \\
\hline $\begin{array}{l}\text { Fat free mass } \\
(\mathrm{kg})\end{array}$ & $45.75 \pm 5.20^{\mathrm{ab}}$ & $47.48 \pm 6.06^{\mathrm{ac}}$ & $49.68 \pm 5.03^{\mathrm{bc}}$ & $\mathbf{0 . 0 0 0 1}$ & $\mathbf{0 . 0 0 0 1}$ \\
\hline $\begin{array}{l}\text { Skeletal } \\
\begin{array}{l}\text { muscle mass } \\
(\mathrm{kg})\end{array}\end{array}$ & $25.09 \pm 3.10^{\mathrm{ab}}$ & $26.08 \pm 3.58^{\mathrm{ac}}$ & $27.35 \pm 2.89^{\mathrm{bc}}$ & $\mathbf{0 . 0 0 0 1}$ & $\mathbf{0 . 0 0 0 1}$ \\
\hline
\end{tabular}

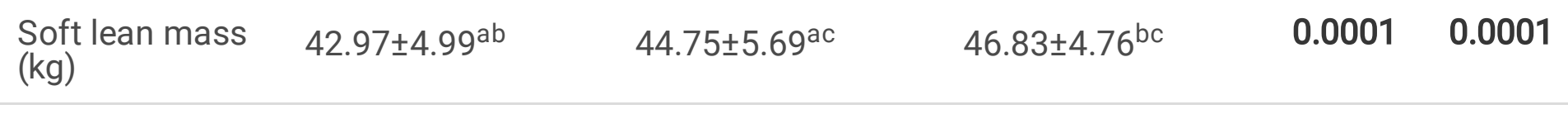

\section{Blood Parameters}

\begin{tabular}{|llllll|}
\hline FBS $(\mathrm{mg} / \mathrm{dl})$ & $86.70 \pm 8.89$ & $89.45 \pm 11.07$ & $88.06 \pm 10.51$ & 0.15 & 0.21 \\
\hline $\begin{array}{l}\text { Insulin } \\
(\mathrm{mll} / \mathrm{ml})\end{array}$ & $15.18 \pm 5.37$ & $16.17 \pm 7.78$ & $16.75 \pm 5.38$ & 0.28 & 0.15 \\
\hline T-Chol $(\mathrm{mg} / \mathrm{dl})$ & $183.22 \pm 33.29$ & $187.80 \pm 38.45$ & $188.10 \pm 41.80$ & 0.60 & 0.34 \\
\hline $\mathrm{TG}(\mathrm{mg} / \mathrm{dl})$ & $120.15 \pm 66.36$ & $128.56 \pm 81.90$ & $116.93 \pm 52.72$ & 0.65 & 0.65 \\
\hline $\mathrm{HDL}-\mathrm{C}(\mathrm{mg} / \mathrm{dl})$ & $46.44 \pm 11.01$ & $46.48 \pm 11.50$ & $47.16 \pm 9.70$ & 0.94 & 0.84 \\
\hline LDL-C $(\mathrm{mg} / \mathrm{dl})$ & $95.76 \pm 23.81$ & $96.00 \pm 24.19$ & $89.43 \pm 24.24$ & 0.39 & 0.37
\end{tabular}




$\begin{array}{llllll}\text { HOMA } & 3.29 \pm 1.34 & 3.67 \pm 2.08 & 3.62 \pm 1.13 & 0.19 & 0.54 \\ \text { ISQUICKI } & 0.548 \pm 0.049 & 0.537 \pm 0.047 & 0.532 \pm 0.043 & 0.10 & 0.02\end{array}$

Dec. RMR, decreased status of RMR; Inc. RMR, increased status of RMR; FFM, fat-free mass; FBS, fasting blood sugar; TG, triglyceride; T-chol, total cholesterol; HOMA, homeostasis model assessment; ISQUICKI, insulin sensitivity quantitative insulin sensitivity check index.

$n=304$

${ }^{*}$ Mean \pm SD. ${ }^{\natural}$ P-values are from ANOVA. $§$ P-values are from general linear model (GLM). ${ }^{\dagger}$ After adjustment for age, FFM, energy intake, and physical activity (METs/d). ${ }^{\ddagger}$ Collinear variables did not enter into the model

Post-Hoc Multiple Comparison analysis from LCD procedure used to demonstrated significant differences between groups

Table 4. The Association of LCDS and RMR across Deviation of Normal RMR

\begin{tabular}{|c|c|c|c|c|}
\hline LCDS & DNR & $\beta$ & OR $(95 \% \mathrm{Cl})$ & $\mathbf{P} \|$ \\
\hline \multirow[t]{2}{*}{ Crude Model } & Dec. RMR & -0.01 & $0.98(0.96-1.01)$ & 0.31 \\
\hline & Inc. RMR & -0.02 & $0.97(0.93-1.01)$ & 0.20 \\
\hline \multirow[t]{2}{*}{ Model1 a } & Dec. RMR & -0.01 & $0.98(0.96-1.01)$ & 0.30 \\
\hline & Incr. RMR & -0.02 & $0.97(0.93-1.01)$ & 0.19 \\
\hline \multirow[t]{2}{*}{ Model $2^{b}$} & Dec. RMR & -0.01 & $0.98(0.95-1.01)$ & 0.24 \\
\hline & Inc. RMR & -0.02 & $0.97(0.94-1.01)$ & 0.24 \\
\hline \multirow[t]{2}{*}{ Model3 ${ }^{c}$} & Dec. RMR & -0.02 & $0.97(0.94-1.00)$ & 0.13 \\
\hline & Inc. RMR & -0.02 & $0.97(0.93-1.01)$ & 0.23 \\
\hline \multirow[t]{2}{*}{ Model4 ${ }^{d}$} & Dec. RMR & -0.02 & $0.97(0.94-1.00)$ & 0.14 \\
\hline & Inc. RMR & -0.02 & $0.97(0.92-1.01)$ & 0.20 \\
\hline
\end{tabular}

LCDS, low carbohydrate diet score; DNR, deviation of normal RMR; Dec. RMR, decreased status of RMR; Inc. RMR, increased status of RMR.

$\mathrm{N}=304$

II P-values are from multinomial logistic regression

Normal RMR status considered as reference category

${ }^{a}$ Model 1: Adjusted for age. ${ }^{b}$ Model 2: Further adjusted for FFM. ${ }^{\mathrm{C}}$ Model 3: Further adjusted for physical activity (METs/d). ${ }^{d}$ Further adjusted for energy intake 
Page 20/22 


\begin{tabular}{|c|c|c|c|c|c|}
\hline & LCDS & DNR & $\boldsymbol{\beta}$ & OR (95\% Cl) & $\mathbf{P} \|$ \\
\hline \multirow[t]{4}{*}{ GL } & \multirow[t]{2}{*}{ Crude model } & Dec. RMR & 0.0001 & $1.00(0.99-1.00)$ & 0.85 \\
\hline & & Inc. RMR & 0.0001 & $1.00(1.00-1.00)$ & 0.57 \\
\hline & \multirow[t]{2}{*}{ Adjusted model ${ }^{a}$} & Dec. RMR & 0.0001 & $1.00(0.99-1.00)$ & 0.65 \\
\hline & & Inc. RMR & 0.0001 & $1.00(1.00-1.00)$ & 0.20 \\
\hline \multirow{4}{*}{$\begin{array}{l}\text { Carbohydrates } \\
\text { (\% energy) }\end{array}$} & \multirow[t]{2}{*}{ Crude model } & Dec. RMR & 0.11 & $1.11(0.95-1.30)$ & 0.15 \\
\hline & & Inc. RMR & 0.18 & $1.20(0.95-1.51)$ & 0.11 \\
\hline & \multirow[t]{2}{*}{ Adjusted model } & Dec. RMR & 0.15 & $1.62(0.98-1.37)$ & 0.08 \\
\hline & & Inc. RMR & 0.19 & $1.22(0.94-1.58)$ & 0.13 \\
\hline \multirow[t]{4}{*}{ MUFA } & \multirow[t]{2}{*}{ Crude model } & Dec. RMR & -0.53 & $0.58(0.27-1.24)$ & 0.16 \\
\hline & & Inc. RMR & -0.42 & $0.65(0.21-0.03)$ & 0.46 \\
\hline & \multirow[t]{2}{*}{ Adjusted model } & Dec. RMR & -0.71 & $0.48(0.21-1.10)$ & 0.08 \\
\hline & & Inc. RMR & -0.60 & $0.54(0.15-1.88)$ & 0.33 \\
\hline \multirow{4}{*}{$\begin{array}{l}\text { Vegetable protein intake } \\
\text { (\% energy) }\end{array}$} & \multirow[t]{2}{*}{ Crude model } & Dec. RMR & -0.11 & $0.89(0.72-1.10)$ & 0.28 \\
\hline & & Inc. RMR & -0.17 & $0.83(0.55-1.25)$ & 0.39 \\
\hline & \multirow[t]{2}{*}{ Adjusted model } & Dec. RMR & -0.21 & $0.88(0.71-1.09)$ & 0.26 \\
\hline & & Inc. RMR & -0.23 & $0.78(0.48-1.29)$ & 0.34 \\
\hline \multirow{4}{*}{$\begin{array}{l}\text { Refined grains } \\
\text { (\% energy) }\end{array}$} & \multirow[t]{2}{*}{ Crude model } & Dec. RMR & 0.001 & $1.00(0.92-1.08)$ & 0.99 \\
\hline & & Inc. RMR & -0.13 & $0.87(0.77-0.99)$ & 0.04 \\
\hline & \multirow[t]{2}{*}{ Adjusted model } & Dec. RMR & -0.008 & $0.99(0.90-1.09)$ & 0.87 \\
\hline & & Inc. RMR & -0.06 & $0.93(0.81-1.08)$ & 0.39 \\
\hline \multirow[t]{4}{*}{ n3/n6 PUFA } & \multirow[t]{2}{*}{ Crude model } & Dec. RMR & 0.33 & $1.40(0.37-5.24)$ & 0.61 \\
\hline & & Inc. RMR & -0.34 & $0.70(0.10-4.78)$ & 0.72 \\
\hline & \multirow[t]{2}{*}{ Adjusted model } & Dec. RMR & 0.61 & $1.84(0.42-7.95)$ & 0.41 \\
\hline & & Inc. RMR & -0.09 & $0.90(0.11-7.41)$ & 0.92 \\
\hline \multirow{3}{*}{$\begin{array}{l}\text { Fiber } \\
\text { (gr/1000Kcal) }\end{array}$} & \multirow[t]{2}{*}{ Crude model } & Dec. RMR & 0.006 & $1.00(0.95-1.05)$ & 0.81 \\
\hline & & Inc. RMR & 0.01 & $1.01(0.94-1.08)$ & 0.75 \\
\hline & Adjusted model & Dec. RMR & 0.0001 & $1.00(0.94-1.05)$ & 0.99 \\
\hline
\end{tabular}




Inc. RMR $\quad 0.06 \quad 1.06(0.97-1.16) \quad 0.14$

LCDS, low carbohydrate diet score; DNR, deviation of normal RMR; Dec. RMR, decreased status of RMR; Inc. RMR, increased status of RMR; GL, glycemic load.

$\mathrm{N}=304$

II P-values are from multinomial logistic regression

The normal RMR status considers as reference category

a adjusted model: adjusted for age, FFM, physical activity (METs/d), energy intake. 